Nada $Z$ Mohammed BDS, MSc (Assist Lect)

\section{The Effect of Thickness of Heat Cured Acrylic Resin with Additives on Water Sorption and Solubility}

Department of Prosthetic Dentistry

College of Dentistry, University of Mosul

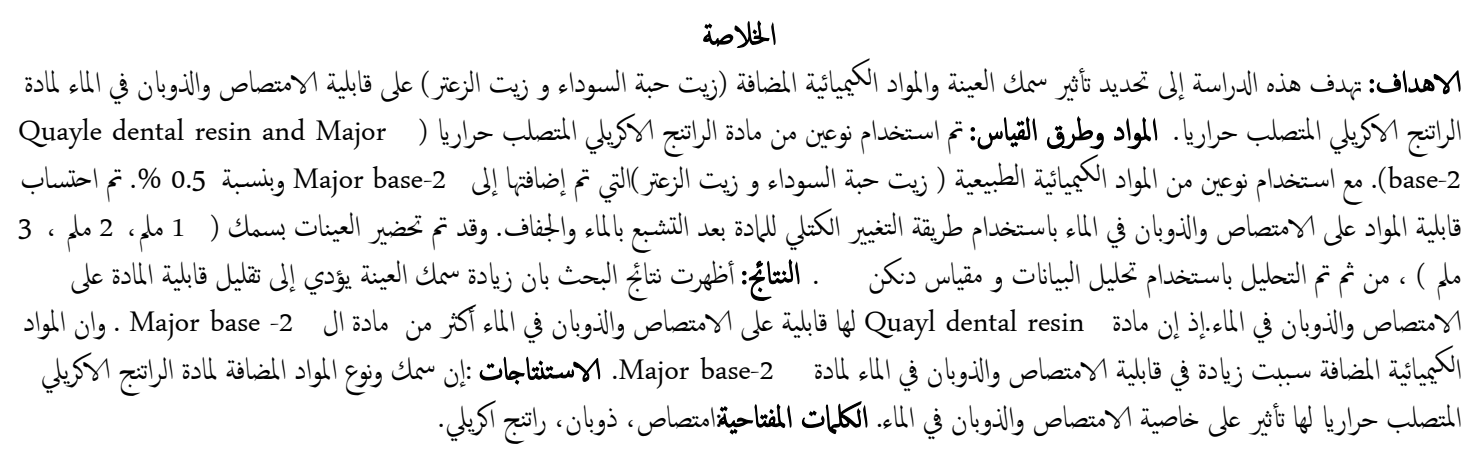

ABSTRACT

Aims : The aims of this study were to determine the effect of thickness and additives (Nigella Stavia oil and Thymol oil) on water sorption and solubility of heat cured acrylic resin denture base. Materials and Methods: Two types of heat cured acrylic resin Quayle dental resin and Major base2 were used. Two additive materials $(0.5 \%)$ have been added to major base 2 which are(Nigella Stavia oil and Thymol oil) . Water sorption and solubility of specimens were measured by mean of mass change in material after water saturation and dehydration. The specimens were prepared in three thicknesses $(1 \mathrm{~mm}$, $2 \mathrm{~mm}$ and $3 \mathrm{~mm}$ ). The effect of thickness on water sorption and solubility also has been measured. The data were analyzed using analysis of variance and Duncan's multiple range tests. Results: Increase thickness causes decrease in water sorption and solubility; Q.D has more water sorption and solubility than major acrylic resin. The two additives caused an increase in the water sorption and solubility of major acrylic resin denture base. Conclusions: The thickness and type of manufacturing materials added into acrylic resin played an important role in determining its water sorption and solubility.

Key words: sorption, solubility, acrylic resin.

Mohammed NZ. The Effect of Thickness of Heat Cured Acrylic Resin with Additives on Water Sorption and Solubility. Al-Rafidain Dent J. 2010; 10(1):169-175.

Received: $21 / 12 / 2008$

Sent to Referees: $21 / 12 / 2008$

Accepted for Publication: 11/3/2009

\section{INTRODUCTION}

Acrylic was introduced to dentistry in $1937^{(1)}$ and to date, no other material has been found that matches the appearance of the oral tissues with as great as fidelity as acrylic resin. It is overall performance is regarded as satisfactory and it is widely used for the construction of complete denture $^{(2-5)}$. The basic material and technique have remained as the denture base material of choice since that time. Although, various polymers have been developed(modification of polymethylmethacrylate by the addition of chemical materials) for the use in dentistry to overcome the strength deficiencies of polymethylmethacrylate $^{(6)}$.

Acrylic resin polymer absorbs water over a period of time. This due to primarily to the polar properties of resin ${ }^{(7)}$. Sorption of material represents the amount of water absorbed on the surface and absorbed into the body of the material during fabrication or while the restoration is in service $^{(8)}$. The absorbed water stays in gaps among the interpolymeric chains that form acrylic resin structure. The magnitude of these interpolymeric gaps determines the amount of water to be absorbed (9). 
Within the establish limit water sorption can be considered a desirable property because it compensates resin polymerization shrinkage, beyond these limits water sorption value can lead to undesirable dimensional alteration ${ }^{(9)}$.

Acrylic resin polymer is not soluble in water, the solubility represents the mass of soluble material that leaches out from polymers. The only soluble materials are initiators, plasticizer and free monomer ${ }^{(10)}$.

Water sorption and solubility were measured by mean of mass change in the material after water saturation and dehydration ${ }^{(11,12)}$.

The aim of this study was evaluating water sorption and solubility of acrylic resin before and after the addition of chemical material(which has been added as a disincentive agents $)^{(13)}$ and compared it with that off acrylic visible light cure(V.L.C). The effect of thickness on water sorption and solubility of new type of acrylic resin also has been evaluated.

\section{MATERIALS AND METHODS}

Two types of heat cured acrylic resin Quayle dental resin and Major base2 were used. The additive materials (Nigella Stavia Oil and Thymol Oil) have been added to the monomer of major base 2 at a percentage of $0.5 \%{ }^{(13)}$. The water sorption and solubility of heat cured (major base 2) acrylic resin have been measured and compared with that after the addition of chemical material and with that of acrylic visible light cure(Megatray,Germaby 2A628D,Pink) ; also the effect of thickness (with and without additive materials) on water sorption and solubility has been evaluated.

The specimens were prepared as disk like with dimension $50 \mathrm{~mm}$ in diameter and with 3 thicknesses $(1 \mathrm{~mm}, 2 \mathrm{~mm}$ and $3 \mathrm{~mm}$, $\pm 0.5 \mathrm{~mm}$ ). A stainless steel matrix with a diameter of $50 \mathrm{~mm}$ has been used to prepare the specimens ${ }^{(11)}$. Five specimens of each material were prepared.

For heat cured resin, the specimens cured in water path with the conventional curing cycle. The specimens processed at $74 \mathrm{c}^{\circ}$ for 1.5 hours , then the temperature of water bath increased the boiling $\left(100^{\circ} \mathrm{C}\right)$ for additional 3 hours ${ }^{(14)}$.
For Visible light cure acrylic resin specimens(V.L.C)

the past packed in mold and kept under hydraulic press for 5 minutes and then the specimens deflasked and transferred to curing in Visible light curing machine(MegalightSt,Megadent,GmbltD0145 4Germany).

After completing the polymerization all acrylic resin specimens were deflasked and finished using tungsten drill and aluminum oxide sand papers(180\#,220\#,400\#) at low speed ${ }^{(4)}$.

The specimens were dried over silica gel in a desicator at $37^{\circ} \mathrm{C}$ and weighted to an accuracy of $0.0001 \mathrm{gm}$ using an electronic balance device(Mettler PM 460, Germany). This was considered to be initial weight of specimens (W1). The specimens then immersed in distilled water ,each specimens being in separated containers. The specimens were removed from their container after 1 week. Excess water was removed by blotting with filter paper and the weight of the specimens was recorded (W2). This represented the weight of the specimen after absorption of distilled water. The specimens were dried by placing in the Disicator. It placed in a recipient containing dry and fresh silica gel which was stored at $37 \pm 1 \mathrm{c}^{\circ}$ during 24 hours. Afterward, the recipient was left bench-cooling for 1 hour until reaching room temperature.

The specimens were weighted in an analytical balance accurate to $0.001 \mathrm{gm}$. This condition cycle was repeated every 24 hours until all specimen(W3) reaches final weight .

The absorption and solubility values were determined as follows ${ }^{(15-19)}$ :

$$
\begin{aligned}
& \text { Absorption }=\frac{w 2-w 3}{w 1} * 100 \\
& \text { Solub ility }=\frac{W 1-W 3}{W 1} * 100
\end{aligned}
$$

The mean and standard deviation were calculated. One way analysis of variance and Duncan's multiple rang test were used to analyze the data and to determine the level of significant difference among the test groups at $P \leq 0.05 \%$ level of significant. 


\section{RESULTS}

The results of the mean values of the water sorption Table(l) showed a decrease in water sorption of acrylic specimens by increasing their thickness. There was a slight mean differences between water sorption of Major and Q.D acrylic resin denture base at $(1 \mathrm{~mm}, 2 \mathrm{~mm}$ and $3 \mathrm{~mm}: 0.003,0.101$ and 0.000 respectively).

Table(1) Mean and standard deviation for the effect of thickness on water sorption of Major ,Q.D and V.L.C acrylic resin

\begin{tabular}{ccccccc}
\hline & $\begin{array}{c}\text { Mean } \\
\mathbf{1 m m}\end{array}$ & SD & $\begin{array}{c}\text { Mean } \\
\mathbf{2 m m}\end{array}$ & SD & $\begin{array}{c}\text { Mean } \\
\mathbf{3 m m}\end{array}$ & SD \\
\hline Major & 1.680 & 0.24 & 1.121 & 0.016 & 0.612 & 0.044 \\
Q.D & 1.607 & 0.115 & 1.014 & 0.043 & 0.612 & 0.063 \\
V.L.C & 0.46 & 0.012 & 0.315 & 0.066 & 0.039 & 0.023 \\
\hline
\end{tabular}

The results of this study showed that the greatest decrease in the water solubility of acrylic specimens Table(2) was with $3 \mathrm{~mm}$ thickness. V.L.C demonstrated less water sorption and solubility than that of both Major and Q.D acrylic resin specimens.

Table(2) Mean and standard deviation for the effect of thickness on water solubility of Major ,Q.D and V.L.C acrylic resin

\begin{tabular}{ccccccc}
\hline & $\begin{array}{c}\text { Mean } \\
\mathbf{1 m m}\end{array}$ & SD & $\begin{array}{c}\text { Mean } \\
\mathbf{2 m m}\end{array}$ & SD & $\begin{array}{c}\text { Mean } \\
\mathbf{3 m m}\end{array}$ & SD \\
\cline { 2 - 7 } Major & 0.885 & 0.187 & 0.585 & 0.044 & 0.199 & 0.039 \\
Q.D & 0.578 & 0.048 & 0.400 & 0.0193 & 0.2841 & 0.094 \\
V.L.C & 0.1347 & 0.079 & 0.07 & 0.033 & 0.029 & 0.02 \\
\hline
\end{tabular}

ANOVA analysis Tables (3and 4) revealed that this statistically significant decrease in water sorption and solubility of both acrylic resins(Major and Q.D) and visible light cure, except that there is no statistic al significant decrease in solubility of V.L.C with increasing the thickness of acrylic resin specimens and that for Q.D acrylic resin specimens at $2 \mathrm{~mm}$ and $3 \mathrm{~mm}$ at $(P \leq 0.05 \%)$.

Table(3) ANOVA for the effect of thickness on water sorption of acrylic resins

\begin{tabular}{|c|c|c|c|c|c|c|c|c|c|c|}
\hline \multirow[b]{4}{*}{ Tested group } & \multirow{3}{*}{ DF } & \multicolumn{9}{|c|}{ Water sorption ratio (weight\%) } \\
\hline & & & Major & & & Q.D & & & V.L.C & \\
\hline & & MS & $\mathbf{F}$ & $\mathbf{P}$ & MS & F & $\mathbf{P}$ & MS & F & $\mathbf{P}$ \\
\hline & 2 & 1.319 & 44.45 & 0.00 & 1.252 & 196.9 & 0.00 & 0.274 & 39.02 & 0.00 \\
\hline Error & 12 & 0.02 & & & 0.006 & & & 0.007 & & \\
\hline Total & 14 & & & & & & & & & \\
\hline
\end{tabular}

Table(4) ANOVA for the effect of thickness on water solubility of acrylic resins

\begin{tabular}{ccccccccccc}
\hline & D & & \multicolumn{4}{c}{ Water solubility ratio (weight \%) } \\
& F & Major & \multicolumn{3}{c}{ Q.D } & \multicolumn{3}{c}{ V.L.C } & \\
\cline { 2 - 11 } Tested group & 2 & 0.591 & 46.03 & 0.00 & 0.114 & 27.24 & 0.00 & 0.337 & 6.46 & 0.00 \\
Error & 12 & 0.012 & & & 0.004 & & & 0.002 & & \\
Total & 14 & & & & & & & & & \\
\hline
\end{tabular}

Statistical analysis revealed that there is no statistically significant difference in water sorption and solubility of Major base2 and Q.D acrylic resin denture base.
However this difference was statistically significant at $(P \leq 0.05 \%)$ between major and V.L.C resins Tables (5and6) 
Table (5) ANOVA for water sorption and solubility of Major base 2 and Q.D acrylic resin

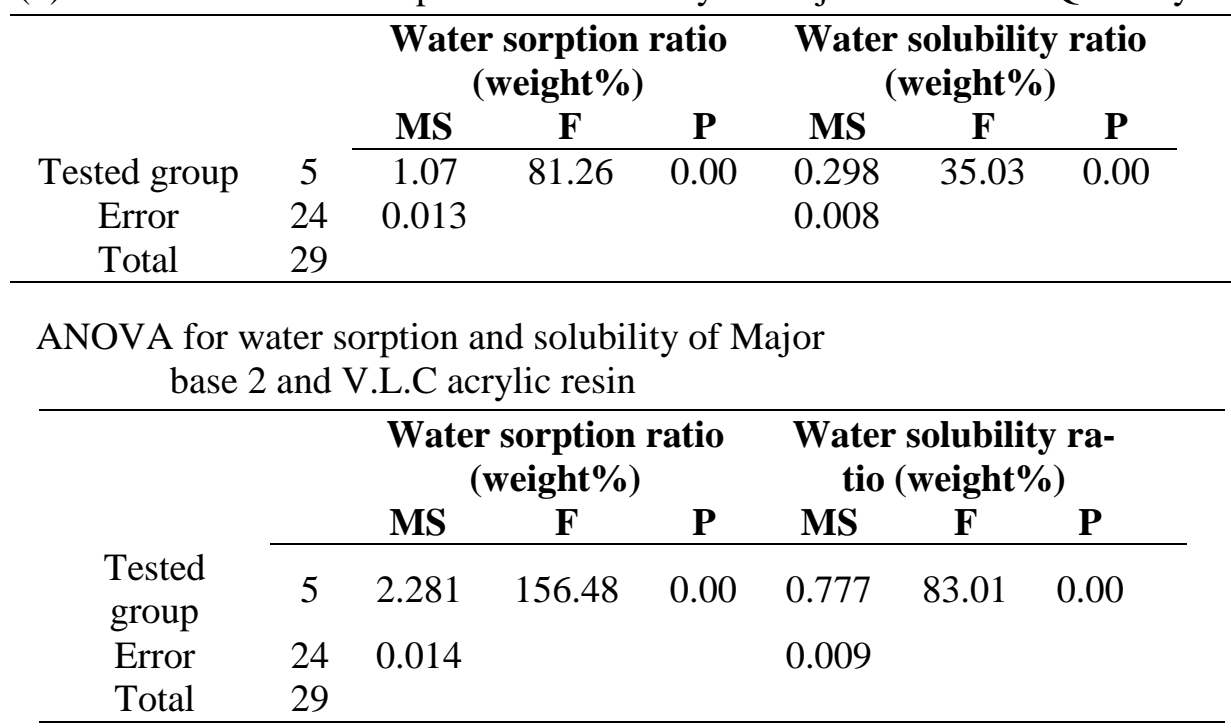

The result of the effect of additives ( Nigella Stavia Oil and Thymol Oil) on water sorption and solubility of Major base2 acrylic resin Table(7and 8) represented that there is an increase in water sorption and solubility of Major acrylic resin after the addition of both nigella stavia oil and thymol oil. This increase in water solubility and sorption was statistically significant increase at $(P \leq 0.05 \%)$ Table (9).

Table(7) Mean and standard deviation for the effect of additives on water sorption of Major acrylic resin

\begin{tabular}{ccccccc}
\hline & $\begin{array}{c}\text { Mean } \\
\text { 1mm }\end{array}$ & SD & $\begin{array}{c}\text { Mean } \\
\text { 2mm }\end{array}$ & SD & $\begin{array}{c}\text { Mean } \\
\text { 3mm }\end{array}$ & SD \\
\cline { 2 - 7 } Major & 1.680 & 0.24 & 1.121 & 0.016 & 0.612 & 0.044 \\
Major+NSO* & 2.489 & 0.0324 & 2.189 & 0.052 & 2.133 & 0.03 \\
Major+OO** & 1.607 & 0.114 & 1.014 & 0.04 & 0.6123 & 0.063 \\
\hline
\end{tabular}

*Nigella Stavia Oil. , ** Thymol Oil.

Table(8) Mean and standard deviation for the effect of additives on water solubility of Major acrylic resin

\begin{tabular}{ccccccc}
\hline & $\begin{array}{c}\text { Mean } \\
\mathbf{1 m m}\end{array}$ & SD & $\begin{array}{c}\text { Mean } \\
\mathbf{2 m m}\end{array}$ & SD & $\begin{array}{c}\text { Mean } \\
\mathbf{3 m m}\end{array}$ & SD \\
\cline { 2 - 7 } Major & 0.885 & 0.187 & 0.585 & 0.044 & 0.199 & 0.039 \\
Major+NSO* & 2.384 & 0.115 & 1.884 & 0.123 & 2.11 & 0.086 \\
Major+OO** & 2.119 & 0.07 & 1.5476 & 0.195 & 1.404 & 0.115 \\
\hline *Nigella Stavia Oil., ** Thymol Oil. & & & & &
\end{tabular}

Table (9) ANOVA for the effect of additives on water sorption and solubility of Major acrylic resin

\begin{tabular}{cccccccc}
\hline & & \multicolumn{3}{c}{$\begin{array}{c}\text { Water sorption ratio } \\
\text { (weight\%) }\end{array}$} & \multicolumn{3}{c}{$\begin{array}{c}\text { Water solubility ratio } \\
\text { (weight\%) }\end{array}$} \\
& & MS & $\mathbf{F}$ & $\mathbf{P}$ & MS & F & P \\
\cline { 3 - 8 } Tested group & 8 & 1.948 & 89.73 & 0.00 & 2.93 & 196.98 & 0.00 \\
Error & 36 & 0.012 & & & 0.014 & & \\
Total & 44 & & & & & & \\
\hline
\end{tabular}


Duncan's multiple range test Figures (1and 2) revealed that there is a statistically significant increase in water sorption and solubility of major acrylic resin before and after the addition of Nigella Stavia oil and Thymol oil, also there is statistically significant decrease in water sorption and solubility with increasing the thickness of prepared specimens at $(P \leq 0.05 \%)$. The percentage of increase of water solubility of major base 2 acrylic resin specimens with the addition of Nigella stavia oil was higher than that with the addition of Thymol oil.

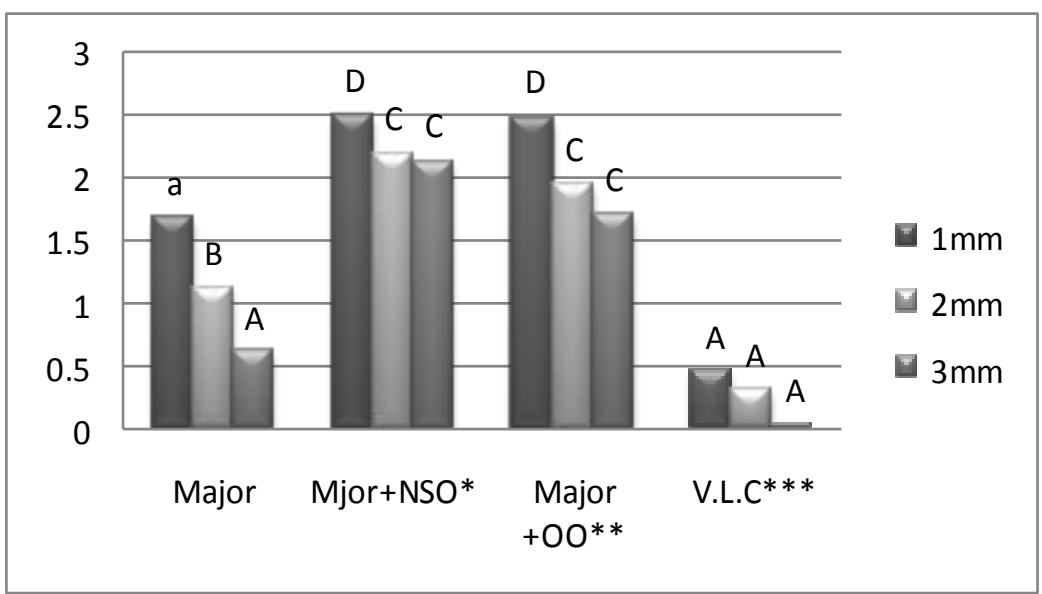

Figure (1) Duncan's multiple range for the water sorption of major base 2 with and without additives and VLC.

*Nigella Stavia Oil; ** Thymol Oil; ***Visible Light Cure; ****different litters $(a, b, c$ and $d)$ mean statistically significant difference at; $p \leq 0.05 \%$ between groups

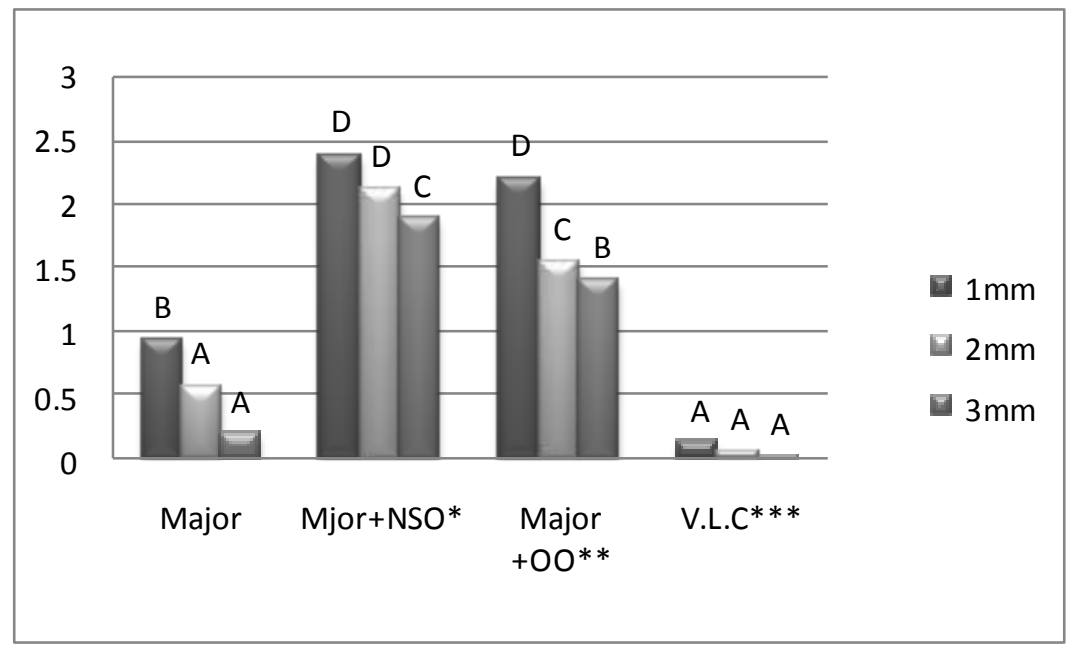

Figure (2): Duncan's multiple range for the water solubility of major base 2 with and without additives and VLC

*Nigella Stavia Oil; ** Thymol Oil; ***Visible Light Cure; ****different litters(a,b,c and d) mean statistically significant difference at; $\mathrm{p} \leq 0.05 \%$ between groups

\section{DISCUSSION}

All types of acrylic resin used in this study demonstrated water sorption and solubility Table(1 and 2) after storage in water. Sorption can be related to the polarity of acrylic resin(due to unsaturated bond $)^{(7)}$. While, solubility can be related to the leach of soluble material that present in 
an acrylic resin (initiator, plasticizer, residual monomer) ${ }^{(20)}$.

The result of this study revealed that there is a decreasing in water sorption and solubility of all acrylic specimens with increasing the thickness of specimens Table(1and 2). This can be related to the decrease in the surface area of specimens that exposed to the action of water and also to the fact that monomer content of resin specimens depends on the thickness of specimens. Thin acrylic specimens had a higher level of residual monomer than thick one ${ }^{(12,21)}$. During polymerization process . Thick acrylic specimens reached a higher temperature(heat evolved during polymerization) resulting in greater degree of polymerization and corresponding reduction in the amount of residual monomer $^{(22)}$.While, for VLC as it is monomer free ${ }^{(18)}$ so that there is no statistically significant decrease in water solubility of the specimens with increasing the thickness of acrylic specimens .

Statistical analysis Table(5) revealed that there is no statistically difference between water sorption and solubility of major base 2 and Q.D acrylic resin. This was in agreement with Ammar et al ${ }^{(19)}$. While a statistically significant difference in water sorption and solubility of major base 2 and VLC Table (6). This can be related to the proper polymerization technique and monomer free content of $\operatorname{VLC}^{(18,22,23-25)}$.

The addition of chemical materials (Nigella Stavia Oil and Thymol Oil) into major base 2 acrylic resin specimens produced a statistically significant increase of its water sorption and solubility Table (7 and 8). The addition of chemical materials caused alteration in molecular resin chain ( modify the magnitude of the polymeric gaps) and consequently alter water sorption and solubility ${ }^{(26)}$. Water sorption and solubility depended on homogeneity of the material $^{(27)}$.

\section{CONCLUSIONS}

Different types of acrylic resin significantly demonstrated varying degree of water sorption and solubility. Increasing the thickness of acrylic specimens produce a statistically significant decreasing in the water sorption and solubility of acrylic specimens. The addition of chemical materials to the Major acrylic resin produce a statistically significant increase in its water sorption and solubility . VLC has low water sorption and solubility than major base 2 acrylic resin. Suggestion: Further study for chemical analysis of resin after addition of chemical material is needed.

\section{REFERENCES}

1. Graig RG Restorative Dental Materials. $11^{\text {th }}$ ed. Mosby Co. Missouri, USA. 2002:Pp:97-112.

2. Bartoloni JA, Murchison DF and Sarkar NK. Degree of Conversion in Denture Base Materials for Varied Polymerization Technique. J. Oral. Rehab. 2000;27:488493

3. Oliveria VM, Leon BL and Consani S. Influence of Number and Position of Flasks in the Monomer Release, Knoop Hardness and Porosity of MicrowaveCured Acrylic Resin. J. Oral. Rehab. 2003;30:1104-1108.

4. Yannikakis S, Zissis A and Andreopoulos A. Evaluation of porosity in Microwave Processed Acrylic Resin Using a Photographic Method. J. Prosthet. Dent. 2002;87:613-619.

5. Wong DM, Cheng LY, Chow TW and Clark RK. Effect of Processing Method on the Dimensional Accuracy and Water Sorption of Acrylic Resin Dentures. J. Prosthet. Dent. 1999;81:300-304.

6. Stafford GD, Bates JF and Handley RW. A Review of the Properties of Some Denture Base Polymers. J Dent. 1980; 8:292306.

7. Philips RW. Skinners Science of Dental Materials. ${ }^{\text {th }}$ Ed. WB Saunders Philladelphia. 1991.Pp: 177-213.

8. Graig RG, O'Brien WJ and Power JM. Dental Materials. $6^{\text {th }}$ Ed. Mosby Co.Missouri, USA. 1996;Pp: 258.

9. Meloto GB, Sil VA-Concilio LR and Rizzatti CM. Water Sorption of HeatPolymerized Acrylic Resins Processed in Mono and Bi Maxillary Flask. Braz. Dent. J. 2006; 17: 122-125.

10. Varpu M, Pekka K and Vallituu U. Water Sorption and Solubility of GlassReinforced Denture Polymethyl Methacrylate Resin. J. Prosthet. Dent. 1996;76(5): 531-534.

11.American Dental Association Specifica- 
tion. Guide to Dental Material And Device. $7^{\text {th }}$ Ed.American Dental Association,211East Chicago,U.S.A. 1975: Pp: 205.

12.Peter P and Ernst UP. Residual Methyl Methacrylate Monomer, Water Sorption and Water Solubility of Hypoallergic Denture Base Materials. J. Prosthet. Dent. 2004:92: 72-78.

13. Nadira $\mathrm{H}$, Amer $\mathrm{T}$, Wafaa A and Arjuan M.The Effect of Thyme and Nigella Oil on Some Properties of Acrylic Resin Denture Base. Accept for Publication 2008.

14.Graig RG and Power JM . Dental Materials properties and manipulation. $8^{\text {th }} \mathrm{Ed}$. Mosby Co. China. 2004:Pp: 271-284.

15.Kazanji M and Watkinson A . Soft Lining Materials: Their Sorption and Solubility in Artificial Saliva. Brit. Dent. J. 1988; 165 : 91-93.

16. Waters MG, Jagger RG and Winter RW. Effect of Surface Modified Fillers on the Water Absorption of a (RTV) Silicone Denture Soft Lining Material. J. Dent.1994; 24: 297-300.

17.Gregory RP and Frederick AR. In Vitro Hardness, Water Sorption and Resin Solubility of Laboratory- Processed and Auto Polymerized Long-Term Resilient Denture Liners Over One Year of Water Storage. J. Prosthet. Dent. 2002; 88: 139-144.

18. Blanca L, Altair A and Renata. Water Sorption, Solubility and Tensile Bond Strength of Resilient Denture Lining Materials Polymerized by Different Method After Thermal Cycling. J. Prosthet. Dent. 2005; 93: 282-287.

19.Ammar K, Ahmad MA and Lamia T. Water Sorption of Heat-Cured Acrylic Resin.Al-Rafidain Dent. J.2007;7:186-194.
20.Takashi A, Hiroshi $M$ and Taizo $H$. Prperties of Highly Cross-Linked Auto Polymerizing Reline Acrylic Resins. J. Prosthet. Dent.1995; 73: 55-59.

21. Shinsuke S, Triyandani G and Takashi A. Influence of Thickness and Location on the Residual Monomer Content of Denture Base Cured byThree ProcessingMethods.J.Prosthet.Dent.1999;72:19-22.

22.Austin A and Basker R. The Level of Residual Monomer in Acrylic Denture Base Materials With Particular Reference to a Modified Method of Analysis. Br. Dent. J. 1980; 149:281-286.

23.Morgana N, Lais $\mathrm{R}$ and Margrate $\mathrm{C}$. Influence of Chemical and Mechanical Polishing on Water Sorption of Acrylic Resins Polymerized by Water Bath and Microwave Irradiation. Braz. J. Oral. Sci. 2007; 6: 1442-1444.

24.Lee SY, Laio YL and Hus TS. Influence of Polymerization Conditions on Monomer Elution and Microhardness of AutoPolymerized Polymethyl Methacrylate Resin. Eur.J.Oral Sci;110:179-183.

25.Salem AL and Dhia I. Effect of Microwave Polymerization on the Level of Residual Monomer in Acrylic Resins. Iraqi. Dent. J. 1999; 24: 255-261.

26.Ana LM, Carlos EC and Maria T. Water Sorption, Solubility and Bond Strength of Two Auto-Polymerizing Acrylic Resins and One Hear-Polymerizing AcrylicResin. J. Prosthet. Dent.1998;80: 434-438.

27. Miettinen $M$ and Vallittu P.Release of Residual Methyl Methacrylate into Water from Glass-Fiber Polymethyl Methacrylate Composite used in Denture.J.Bio Materials.1997; 18: 181-185. 